\title{
Cytomegalovirus infection and risk of new-onset diabetes after transplantation: a retrospective analysis
}

\author{
Muhammad Tassaduq Khan
}

Department of Renal Transplant Unit, Dow University Hospital, Karachi, Pakistan

Background: New-onset diabetes after transplantation (NODAT) is a well-established complication among kidney transplant recipients and is considerably associated with high risk of infectious disease complications. The present research study was aimed to identify whether cytomegalovirus (CMV) infection acts as risk factor for NODAT development in kidney transplant recipients.

Methods: This retrospective study recruited 59 kidney transplant recipients (43 males and 16 females) between March 2017 and February 2019. The diagnosis of NODAT was established if two fasting plasma glucose readings were $\geq 126 \mathrm{mg} / \mathrm{dL}$ after the $3 \mathrm{rd}$ month of post-transplantation. We carefully monitored recipients for CMV viremia (CMV DNA copies/mL) in the plasma through quantitative polymerase chain reaction (qPCR). The 1-year post-transplantation allograft outcomes due to CMV viremia were also measured: estimated glomerular filtration rate (the Chronic Kidney Disease Epidemiology Collaboration method), allograft and transplant patient survival.

Results: The mean age of the kidney transplant patients was $43.4 \pm 6.2$ years. In the present study, 45 patients (76.3\%) were found to have no NODAT (controls), while 14 patients (23.7\%) were diagnosed with NODAT. The CMV load and CMV viremia was elevated in NODAT cohort in comparison with their control counterparts (4,000 vs. 3,600 and 51.1 vs. 47.6 , respectively); however, no statistical relationship was observed ( $P=0.79$ and $P=0.84$, respectively). We witnessed that there was significantly high CMV DNA replication in first (1-6 months) half of the post-transplant period in both controls and NODAT patients; however, statistically significant CMV DNA replication was only observed for NODAT cohort $(\mathrm{P}<0.001)$. Majority of the NODAT diagnosis; nine out of 14 (64.3\%), in our cohort was made during the first 6 months of kidney transplantation $(P<0.001)$.

Conclusions: the present study demonstrated that CMV infection is not a risk factor for NODAT development among kidney transplant recipients. The early diagnosis and rigorous treatment and control of both CMV infection and NODAT could potentially improve the allograft and patient survival.

Corresponding author: Muhammad Tassaduq Khan

E-mail: Muhammad.tassaduq@duhs.edu.pk

(C) The Korean Society for Transplantation

This is an Open Access article distributed under the terms of the Creative Commons Attribution Non-Commercial License (http://creativecommons.org/licenses/by-nc/4.0/) which permits unrestricted non-commercial use, distribution, and reproduction in any medium, provided the original work is properly cited. 